colleagues (13 August, $p$ 455) in the work of Dr D J Betteridge and his colleagues (9 July, p 127). It has the further advantages over the 3-hydroxy-3-methylglutaryl coenzyme-A reductase assay of being technically easier and considerably less expensive.

We would like to express our thanks to Professor J K Lloyd for her help in obtaining skin fibroblasts from subjects I and II. We would also like to thank the patients and their families for the help they have given us in these studies. This work was supported by the British Heart Foundation (award No 578).

A D Postle

D SHEPPARD

I M HILTON

D C Siggers

University of Southampton
Clinical Genetics Group,

Clinical Genetics Group,

Southampton

${ }^{1}$ Goldstein, J L, and Brown, M S, Proceedings of the National Academy of Sciences of the USA, 1973,

Khachadurian, A K, and Kawahara, F S, fournal of Laboratory and Clinical Medicine, $1974,83,7$. Avigan, J, Bhathena, S J, and Schrein
fournal of Lipid Research, 1975, 16, 151 .

Journal of Lipid Research, 1975, 16, 151.
han, B E, and Knowles, B R, Fournal of Lipid Research, 1976, 17, 176.

Research, 1976, 17, 176 .
Kandutsch, A A, and Chen, H W, fournal of Bio-

logical Chemistry, 1973, 248, 8408 .

\section{Changing pattern of alcoholic liver disease}

SIR,-The report by Dr N Krasner and others (11 June, $p$ 1497) provides interesting information on sex differences in immune response to alcohol hepatotoxicity.

Between 1963 and 1966 Pachas and I found that $19^{\circ}$ of patients with Laennec's cirrhosis had positive tests for antinuclear antibody. ${ }^{1}$ In this population $38^{\circ}$ " were women, suggesting that the changing pattern noted by $\mathrm{Dr}$ Krasner and his colleagues in London was heralded by events in Boston almost a decade previously. Although positive antinuclear antibody tests were found more frequently and in higher titre in women than in men, the differences were not significant and these data were not included in our report.

We described 13 patients, 12 of whom were women, with a transient polyarthritis, usually occurring during the phase of recovery from hepatic necrosis. The cause of this rheumatic syndrome was unclear but it certainly may have been related to circulating immune complexes, with antigens of bacterial or hepatic origin. I would be most interested to know whether Dr Krasner and his colleagues encountered such patients in their extensive experience.

\section{Upstate Medical Center,
Syracuse, New York}

' Pachas, W N, and Pinals, R S, Arthritis and Rheumatism, 1967, 10, 343 .

** We sent a copy of this letter to Dr Krasner,

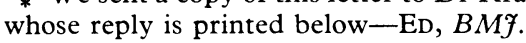

SIR,-I am grateful to Dr Pinals for his interest in our paper. I have now had an opportunity to discuss his letter with my former colleagues at the Liver Unit, King's College Hospital. We find unfortunately that there are no data available on the question of circulating immune complexes and rheumatic syndrome from within the unit and we therefore feel that we are unable to offer a useful comment on this question, although we consider it an interesting possibility.

Wycombe General Hospital,

N KRASNER High Wycombe, Bucks

\section{Screening children for visual defects}

SIR,-In your leading article (3 September, p 594) the need for orthoptist participation in preschool vision screening is identified. A preschool vision screening programme run by orthoptists is already effective in this area. The problem of finding accommodation for orthoptic screening has been solved by setting up a simple motor caravan as a mobile unit. This is a practical way of providing transport and standard conditions and equipment for testing. The initial outlay and running costs are justified by the increased early detection of abnormalities and reduction of inappropriate referrals to eye clinics. Of the children screened, $9^{\circ}$. have been discovered to have defects requiring treatment. A further $60^{\prime \prime}{ }^{\circ}$ were "false-positives" and at least haif of these avoided referral to hospital.

Until resources are available for primary orthoptic screening health visitors receive guidance from orthoptists on basic squint identification and are asked to refer from their routine screening of children at 8 months and 3 years. Two orthoptists, each working in the mobile unit for two days per week, alternating with their normal duties (to relieve tedium), are expected to see 6000 children per year.

This orthoptic screening does not include refraction. Orthoptic techniques can now select children in need of refraction as well as those with squint and amblyopia and can then refer children appropriately to ophthalmologists and opticians in eye clinics.

A Vivien MacLellan P HARKER

Oxfordshire Area He lth Authority (Teaching),

Health Offices,

\section{Vision screening in older children}

SIR,-While fully agreeing with Dr J H Cameron (10 September, p 701) that preschool screening to identify children with defects of vision is of great importance if children are to benefit from early treatment, we are concerned about the supposition that "as the preschool screening procedure develops, so the ophthalmic unit's commitment to the traditional school eye clinics will be reduced and ultimately these clinics will disappear."

We are currently engaged in assessing the results of vision screening of a large and nationally representative sample of schoolchildren at ages 7,11 , and 16 . The data referred to are part of those collected by the National Child Development Study, which is a longitudinal study of all children in England, Scotland, and Wales born in one week in March 1958. At each age distant vision was screened

with a standard Snellen chart at 20 feet $(6 \mathrm{~m})$. The table below shows that of 6634 children in the study with normal $(6 / 6,6 / 6)$ vision at 7 years, $496(7 \cdot 4 \%)$ had a bilateral defect of vision (6/12 in the better eye) by 16 years. To give two other examples, no fewer than $60 \%$ of those with bilateral severe defects at 16 had had normal vision at 7 and $12 \%$ of children with normal vision at 11 showed at least a one-line deterioration in visual acuity by 16 .

These initial results clearly illustrate that visual defects may first become manifest at any stage in childhood and that if a child has normal vision at 7 this is no guarantee that his vision will not deteriorate. We should therefore like to stress the importance of careful, continued, regular vision screening at school as well as preschool screening.

Catherine Peckham

Department of Community Mcdicine,

Charing Cross Hospital Medical

London W6

National Children's Bureau,

Alan TibBenham

London FC.1

\section{An epidural service}

SIR,- The successful employment of extradural analgesia in labour by the obstetric staff of Bowthorpe Maternity Hospital, Wisbech, reported by $\mathrm{Mr}$ A B W Taylor and his colleagues (6 August, p 370), calls for congratulation. It is arguable that if this type of pain relief is routinely undertaken by obstetricians well trained in the use of the technique women in labour will benefit. The obstetrician will be personally involved and responsible for the success of the method much more than if an outsider from the anaesthetic department has inserted the catheter. It is quite certain, however, that very occasionally a total spinal injection will result whoever handles the needle in this area of "tiger country," and when it occurs with gross hypertension, severe cardiovascular collapse, and apnoea skilled and prompt treatment will be necessary in order to save the life of the mother and probably the child as well. This will include intermittent positive pressure ventilation, elevation of the legs of the patient, the rapid infusion of a plasma volume expander, and intravenous injection of a pressor drug.

But why all this anxiety about the passage of a tracheal tube (Dr J M Anderton, 24 September, p 832)? Surely inflation of the lungs can be performed perfectly well without a tracheal tube being in place. Only a wellfitting mask, a pharyngeal airway, a source of oxygen under pressure (or, failing that, a selfinflating bag using air) will be required. Does the apnoea associated with electric convulsion therapy require a tracheal tube for its management? An obstetrician who can be taught to insert a catheter into the extradural space can be taught how to ventilate an apnoeic patient. Psychiatrists have succeeded well enough and

Visual acuity at 16 of children with normal vision at 7

\begin{tabular}{|c|c|c|c|c|c|}
\hline $\begin{array}{c}\text { Normal } \\
(6 / 6,6 / 6)\end{array}$ & $\begin{array}{c}\text { Minor defect } \\
(6 / 6 / 6 / 9 \text { or } \\
6 / 9 / 6 / 9)\end{array}$ & \begin{tabular}{|c|} 
Unilatera! defect \\
$(6 / 6$ or $6 / 9$ in \\
better eye, $6 / 12$ or \\
worse in other eye $)$
\end{tabular} & $\begin{array}{c}\text { Moderate } \\
\text { bilateral defect } \\
(6 / 12 \text { or } 6 / 18 \text { in } \\
\text { better eye })\end{array}$ & $\begin{array}{c}\text { Severe } \\
\text { bilateral defect } \\
\text { (6/24 or worse in } \\
\text { better eye })\end{array}$ & Total \\
\hline $5413\left(81 \cdot 6^{\circ}{ }_{11}\right)$ & $476(7 \cdot 2 \%)$ & $249\left(3 \cdot 8^{\circ}\right)$ & $208(3 \cdot 1 \%)$ & $288(4 \cdot 3 \%)$ & $6634\left(100^{\prime \prime}\right)$ \\
\hline
\end{tabular}

